\title{
Characterizing the Prevalence and Types of Curricular Tracks in Internal Medicine Residency Training Programs
}

J Gen Intern Med 36(10):3273-5

DOI: $10.1007 / \mathrm{s} 11606-020-06419-4$

(c) Society of General Internal Medicine 2021

\section{INTRODUCTION}

Internal Medicine (IM) residency programs have traditionally provided similar, generalized training for all residents. However, in recent decades, specialized training "tracks" have emerged within IM residencies. In response to national shortages and supported by funding from the Health Resources and Services Administration's Primary Care Training and Enhancement: Residency Training in Primary Care Programs, primary care tracks (PCTs) were introduced in the 1970s to attract skilled primary care physicians. ${ }^{1,2}$ In the 1990 s, the field of "hospital medicine" was established, catalyzing the development of hospitalist tracks. ${ }^{3}$ Research tracks, clinicianeducator tracks, and others soon followed. ${ }^{4}{ }^{5}$ Though PCTs have been characterized in the literature, ${ }^{6}$ a recent report on all available tracks is lacking. We investigated the prevalence and types of curricular tracks offered across all US Accreditation Council for Graduate Medical Education (ACGME)accredited IM residency programs. Our goal was to better inform current and future discussions on iterative changes to residency curricula.

\section{METHODS}

We compiled a list of all US ACGME-accredited IM programs from the ACGME website $(n=539)$. From December 2019 to June 2020, we used a data abstraction tool to review each program for track offerings in two publicly available sources: (1) American Medical Association's Fellowship and Residency Electronic Interactive Database Access System (FREIDA ${ }^{\mathrm{TM}}$ ), and (2) residency program websites. Understanding the potential for outdated information, we included all reported tracks from either source and did not directly contact programs for data clarification. In FREIDA ${ }^{\mathrm{TM}}$, we used the program search feature to identify IM programs with primary care, hospitalist, women's health, and rural health tracks; we reviewed each program's individual FREIDA ${ }^{\mathrm{TM}}$ webpage for presence of research and "other" tracks. In program website reviews, we

Received July 10, 2020

Accepted December 8, 2020

Published online January22, 2021 considered any listed "pathway," "track," "area of distinction," or focused program offered within the residency to be a track. We collectively reviewed 10 program websites to revise our data abstraction tool and train reviewers. Three investigators (E.H., J.C., E.R.) independently reviewed the remaining programs, with regular adjudication sessions to reconcile challenges.

\section{RESULTS}

Of the 539 US IM residency programs, 529 (98\%) had program websites for review, $435(81 \%)$ had track information included on FREIDA ${ }^{\mathrm{TM}}, 431(80 \%)$ had information in both sources, and $6(1 \%)$ had no data available for review. Of the 533 reviewed programs, $258(48 \%)$ reported no tracks, 99 (19\%) had 1 track, 85 (16\%) had 2 tracks, 79 (15\%) had 3-5 tracks, and $12(2 \%)$ had 6 or more tracks. The most prevalent track types were primary care $(n=228,43 \%)$, hospitalist $(n=$ $115,22 \%)$, and research $(n=82,15 \%)$ (Table 1). Of programs with $\geq 1$ track, $83 \%$ included a PCT, and $64 \%$ offered multiple track types. There was notable discordance between the data identified from program websites and FREIDA ${ }^{\mathrm{TM}}$ (Fig. 1). Out of the 654 total distinct tracks identified, 192 (29\%) were reported on both FREIDA ${ }^{\text {TM }}$ and program websites, 294 $(45 \%)$ were reported only on FREIDA ${ }^{\mathrm{TM}}$, and $168(26 \%)$ were reported only on program websites.

\section{DISCUSSION}

Our findings highlight the individualization of US IM residency training, as greater than $50 \%$ of programs offered at least one track, and 21 different track types were reported. Most programs offering track(s) included one in primary care, suggesting that, with the Health Resources and Services Administration's support, many IM residency programs are striving to fill primary care needs. Programs with any track were likely to have two or more tracks, which may reflect the start-up resources and experience necessary to create specialized curricular opportunities. Potential drivers for track development include diverse workforce needs, learner attraction, and funding support. Tracks may better prepare residents for their specific career goals, encourage trainees to fill workforce gaps, and attract residency and faculty candidates with particular areas of interest and expertise. The significant discrepancies in track reporting between the two sources present a challenge and 
Table 1 Results of US Internal Medicine Residency Track Type and Prevalence (2020)

\begin{tabular}{|c|c|c|c|}
\hline \multirow[b]{2}{*}{ Track type } & \multicolumn{3}{|c|}{ Number of programs with track reported, $n$ (\% of programs) } \\
\hline & $\begin{array}{l}\text { Website review } \\
(n=529 \text { programs })\end{array}$ & $\begin{array}{l}\text { FREIDA }{ }^{\mathrm{TM}} \text { review } \\
(n=435 \text { programs })\end{array}$ & $\begin{array}{l}\text { Total distinct tracks } \\
(n=533 \text { programs })^{\mathrm{a}}\end{array}$ \\
\hline Primary care & $104(20)$ & $219(50)$ & $228(43)$ \\
\hline Hospitalist & $33(6)$ & $107(25)$ & $115(22)$ \\
\hline Research & $61(12)$ & $46(11)$ & $82(15)$ \\
\hline Clinician educator & $45(9)$ & - & $45(9)$ \\
\hline Global health & $42(8)$ & - & $42(8)$ \\
\hline Women's health & $9(2)$ & $23(5)$ & $25(5)$ \\
\hline Rural health & $2(1)$ & $22(5)$ & $22(4)$ \\
\hline Quality improvement & $13(2)$ & - & $13(2)$ \\
\hline Leadership & $12(2)$ & - & $12(2)$ \\
\hline Urban health & $7(1)$ & - & $7(1)$ \\
\hline Human immunodeficiency virus (HIV) & $7(1)$ & - & $7(1)$ \\
\hline Geriatrics & $5(1)$ & - & $5(1)$ \\
\hline Subspecialty & $4(1)$ & - & $4(1)$ \\
\hline Equity/inclusion medicine & $4(1)$ & - & $4(1)$ \\
\hline Community health/social medicine & $3(1)$ & - & $3(1)$ \\
\hline Ethics & $2(1)$ & - & $2(1)$ \\
\hline Innovation and design & $2(1)$ & - & $2(1)$ \\
\hline Integrative medicine & $2(1)$ & - & $2(1)$ \\
\hline Critical care & $1(1)$ & - & $1(1)$ \\
\hline Osteopathic manipulative medicine & $1(1)$ & - & $1(1)$ \\
\hline Procedures & $1(1)$ & - & $1(1)$ \\
\hline Other & - & $69(16)$ & $31(6)^{\mathrm{b}}$ \\
\hline Total number of tracks & 360 & 486 & 654 \\
\hline
\end{tabular}

${ }^{a}$ When the same track type was reported on both website and FREIDA ${ }^{T M}$ reviews, a single track was counted in the "Total Distinct Tracks" column ${ }^{b}$ When the presence of an "other track" was listed on FREIDA ${ }^{T M}$, these were assumed to correspond with tracks detailed on websites when possible (e.g., "other track" designated in FREIDA ${ }^{T M}$, and a leadership track identified on the website). In 31 cases, there was an "other track" listed on FREIDA ${ }^{T M}$ without any clear corresponding track detailed on the website so these were unable to be classified further but were included in the total track count

highlight a limitation. Inaccurate or outdated material could not be reconciled without directly contacting each program. This presents an obstacle to student, resident, and faculty consumers of these resources as they explore training opportunities offered by residency programs. Despite its limitations, this study characterizes an evolving trend in US IM residency programs to further individualize training and prepare residents to meet the increasingly complex needs of patients and health systems.

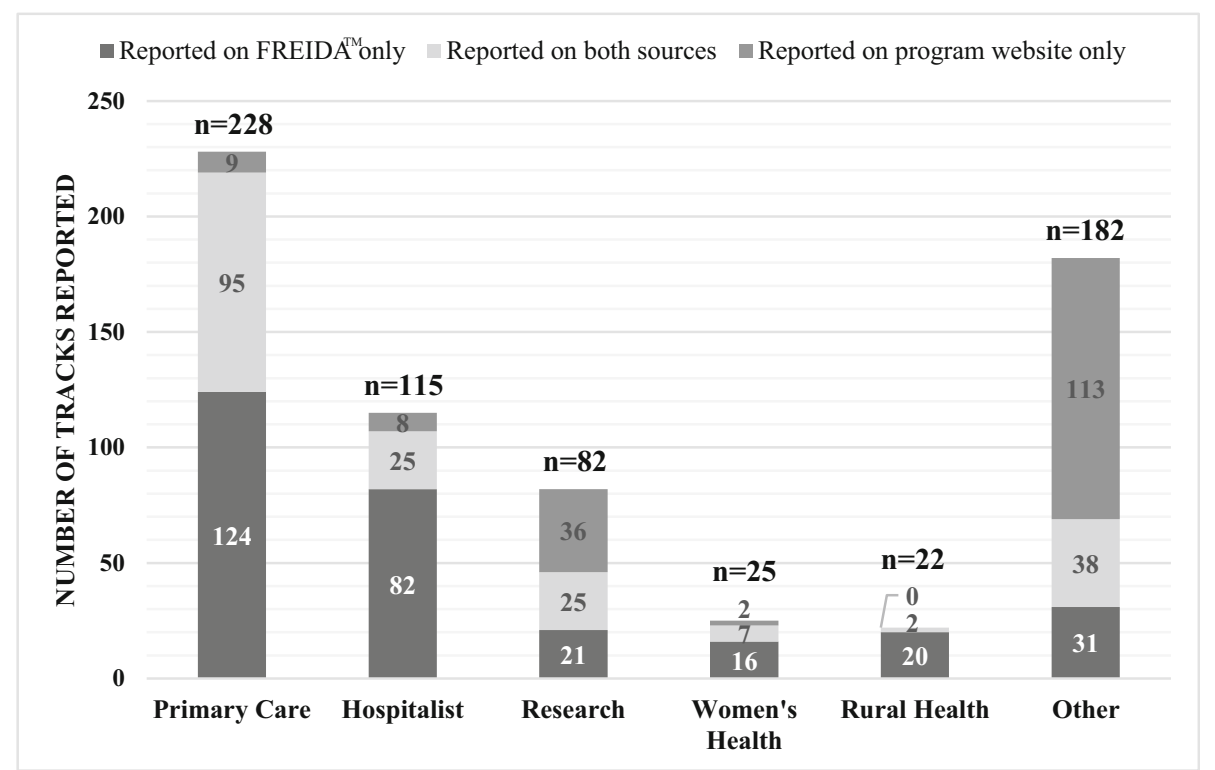

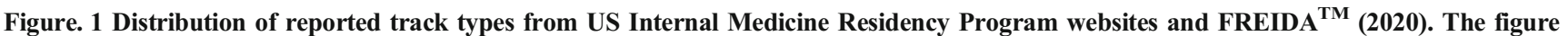
depicts the distribution of reported tracks in US Internal Medicine Residency Programs as identified by review of program websites and the Fellowship and Residency Electronic Interactive Database Access System (FREIDA ${ }^{\mathrm{TM}}$ ) database. Track types are listed under each column ( $x$ axis), and the number of tracks from each data source (e.g., FREIDA ${ }^{\mathrm{TM}}$, website, or both) is depicted within each column ( $y$-axis). The total number of tracks identified of each type is reported as " $n$ " atop each column. 
Acknowledgments: The authors would like to thank the resident and faculty physicians in the Department of Medicine at the Penn State College of Medicine for their dedication to patient care and education.

Eliana V. Hempel, $M D^{1,2}$

Jennifer L. Cooper, $M D^{1,2}$

Elizabeth Raoof, MEd $^{1}$

Jed D. Gonzalo, MD MSc $c^{1,2}$

${ }^{1}$ Penn State College of Medicine,

Hershey, PA, USA

${ }^{2}$ Division of General Internal Medicine, Penn State

Hershey Medical Center - H039,

Hershey, PA, USA

Corresponding Author: Eliana V. Hempel, MD; Division of General Internal Medicine, Penn State Hershey Medical Center - H039, Hershey, PA, USA (e-mail: ehempel@pennstatehealth.psu.edu).

Authors' Contributions Concept and design: Cooper, Gonzalo, Hempel

Acquisition, analysis, or interpretation of data: Cooper, Gonzalo, Hempel, Raoof

Drafting of the manuscript: Cooper, Gonzalo, Hempel, Raoof

Critical revision of the manuscript for important intellectual content:

Cooper, Gonzalo, Hempel, Raoof

Data Availability The dataset is available upon request.

\section{Compliance with Ethical Standards}

Conflict of Interest: The authors declare that they do not have a conflict of interest.

Ethical Approval: Reported as not applicable.

Disclaimers: The content of and views expressed in this paper reflect the views of the authors and do not necessarily represent the views of the AMA, Josiah Macy Jr. Foundation, or other participants in the Accelerating Change in Medical Education initiative.

\section{REFERENCES}

1. AAMC. The complexities of physician supply and demand: projections from 2017 to 2032. April 2019

2. Burke W, Inui TS. Do we still need primary care tracks? Ann Intern Med 1992; 116(12 Pt 2): 1065-70.

3. Hauer KE, Flanders SA, Wachter RM. Training future hospitalists. West $\mathrm{J}$ Med. 1999; 171(5-6): 367-370.

4. Smith CC, McCormick I, Huang GC. The clinician-educator track: training internal medicine residents as clinician-educators. Acad Med. 2014; 89(6): 888-91.

5. Kohlwes RJ, Shunk RL, Avins A, Garber J, Bent S, Shlipak MG. The PRIME curriculum: clinical research training during residency. J Gen Intern Med. 2006; 21(5): 2250-2255.

6. Klein R, Alonso S, Anderson C, et al. Delivering on the promise: exploring training characteristics and graduate career pursuits of primary care internal medicine residency programs and tracks. J Grad Med Ed. 2019:449-453.

Publisher's Note: Springer Nature remains neutral with regard to jurisdictional claims in published maps and institutional affiliations. 